\title{
Digital Socialism Beyond the Digital Social: Confronting Communicative Capitalism with Ethics of Care
}

\author{
Donatella Della Ratta
}

John Cabot University, Rome, Italy, ddellaratta@johncabot.edu

\begin{abstract}
This paper analyses the role of the "social" in communicative capitalism. It shows how the digital social is situated in the context of ideology, exploitation, and alienation. Based on the ethics of care, the essay outlines foundations of an alternative concept and reality of the social in digital socialism. It borrows the key concept of "care" from feminist theory and ethics and uses it to explore alternative paths to rethink "digital socialism" in the age of social media ubiquity and the pervasiveness of communicative capitalism. We need imaginative efforts to think beyond "capitalist realism" as a "pervasive atmosphere" (Fisher 2009, 16) that impacts not just the economy and cultural production, but also the domain of the ideas to the extent that it seems "impossible even to imagine a coherent alternative to it" (Fisher 2009, 2).
\end{abstract}

Keywords: digital socialism, communicative capitalism, social media, care economy, feminist theory, ethics of care

Sharing is the mildest form of socialism

Kevin Kelly, 2009

\section{In the Rubble of the Commons, the Triumph of the "Social"}

"[l]t is easier to imagine the end of the world than it is to imagine the end of capitalism", Mark Fisher wrote in 2009, inspired by Jameson and Žižek's reflections in addressing what he dubbed as "capitalist realism" (Fisher 2009, 2). Fisher describes capitalist realism as "the widespread sense that not only is capitalism the only viable political and economic system, but also that it is now impossible even to imagine a coherent alternative to it" (Fisher 2009, 2). Capitalist realism is such a "pervasive atmosphere" that it does not only invest the domain of economy and cultural production, but also affects and infects that of the imagination, colonizing the latter to the point that "there is no alternative" 1 , not even in conceiving ideas opposing the current hegemony.

Ten years after Fisher wrote his seminal essay - and two years after he tragically took his own life ${ }^{2}$ - the seeming ineluctability of capitalist realism has been further strengthened by what today manifests as its quintessential appearance, its octopus-

\footnotetext{
${ }^{1}$ Margaret Thatcher's famous slogan.

${ }^{2}$ Capitalist Realism frames the problem of depression, a disease of which Fisher himself suffered, within the dysfunctionalities of capitalism, something that cannot be properly healed if conceived as a private problem. "I want to argue that it is necessary to reframe the growing problem of stress (and distress) in capitalist societies. Instead of treating it as incumbent on individuals to resolve their own psychological distress, instead, that is, of accepting the vast privatization of stress that has taken place over the last thirty years, we need to ask: how has it become acceptable that so many people, and especially so many young people, are ill? The 'mental health plague' in capitalist societies would suggest that, instead of being the only social system that works, capitalism is inherently dysfunctional, and that the cost of it appearing to work is very high" (Fisher 2009, 19).
} 
like aspect, i.e. communication. With her conceptualisation of "communicative capitalism", Jodi Dean (2005) provides a powerful description of both the material infrastructure lying beneath networked communications technologies, and of the ideological formation materialising values - such as participation, inclusion, access - that are "heralded as central to democracy" (Dean 2010, 4). Other scholarly reflections offered, such as "platform capitalism" (Srnicek 2016), "data capitalism" (Mayer-Schönberger and Ramge 2018), or "surveillance capitalism (Zuboff 2019), all attribute a central role to the (control over the) production and distribution of communicative in shaping contemporary capitalist realism.

The ever-expanding communicative dimension of contemporary capitalism becomes even more pervasive as it embraces the form of self-disclosed, user-generated and peer-produced bits of content circulating over social networking sites. As McKenzie Wark notices, today's "spectacle", far from being the top-down managed formation described by Debord (1994), whether in its "concentrated" or "diffused" version, is rather "disintegrating" (Wark 2013) in that it is being produced and re-produced by users themselves. The "spectacle 2.0" (Briziarelli and Armano 2017) is the offspring of an environment where the imperative of participation, enabled and empowered by the technological infrastructure of web 2.0 (O'Reilly 2005) and imposed by the business model of the sharing economies ${ }^{3}$, has pushed users to generate a never-ending stream of data.

Capitalist realism thrives on these seemingly endless communicative exchanges produced by all sorts of digital labour - paid and unpaid, under-paid and volunteer work -, in which those formerly known as passive spectators are finally turned into "proactive makers of their own subjugation disguised as free choice and creative expression" (Della Ratta 2018, 181). Users are rendered into peer-creators of this networked spectacle that has replaced "the monologue of appearances (of the traditional spectacle) with the appearance of dialogue" (Wark 2013, 6), paving the way to a "political-economic formation in which there is talk without response" (Dean 2009, 24). While these peer-produced and shared communicative exchanges constitute the non-stop engine thanks to which communicative capitalism thrives, those who generate them are caught into a Sisyphean mechanism where they are condemned to unending activities of constantly making, sharing, and circulating content. In the pursuit of what is rendered into daily, repetitive tedious tasks ${ }^{4}$, such as updating, posting, and sharing, users become cogs within what Byung-Chul Han calls the "burnout society" (Han 2015), blaming themselves for not coping with the latter's demanding pace.

FOMO, or the fear-of-missing-out, which results in a compulsive drive toward nonstop online engagement, is an increasingly common side effect of the contemporary approach to the digital ${ }^{5}$. In a recent ethnographic research that I have conducted with

${ }^{3}$ Originally, the sharing economy as a concept formulated by Lessig (2008) hints at an economy based on non-monetary exchanges. However, as this essay will show, the original concept has been dramatically impacted by business models introduced by platforms such as AirB\&B that maintain the word "sharing" in their slogan but have capitalised on relationships and human exchanges. Lessig himself has acknowledged the failure of the sharing economy in a lecture given at John Cabot University in March 2018 https://www.youtube.com/watch?v=Wgi1WJTtp1g

${ }_{4}$ My ethnographic research shows that these are increasingly described as "tedious", "repetitive" actions even by generation Z, and often depicted as "tasks", something closer to work obligations than fun and leisure activities. See Della Ratta (forthcoming).

${ }^{5}$ See Murphy (2013). 
my undergraduate class "Selfies and Beyond: Exploring Networked Identities", a student wrote:

a large portion of my anxiety and subconscious impulse to engage in social media is the fear of losing touch. It is difficult to grasp how such a culture rooted in interconnection could result in losing contact with people, but this sense of a constant flow of information and communication makes me feel as though I need to always be on top of things, or else I will fade into the background (Della Ratta forthcoming).

Another student concluded, after admitting being haunted by ghost buzzing, as if her phone would continuously notify her with new (inexistent) messages:

I have never tried to be offline. I know it's completely impossible, and I know my existence would be much more serene and relaxed. Free from any kind of anxiety or tension. I remember when it seemed a miracle to have unlimited minutes and messages in the phone tariff. Now, the only thing that should not have an end is the Internet (Della Ratta forthcoming).

Far from being a liberating environment, thriving on free expression and creativity, the domain of digital communicative exchanges seems to be haunted by new, increasingly complicated forms of stress, depression, and anxiety disorders. As envisaged by Fisher, these statutes are largely processed as individual diseases or disabilities, never as endemic forms to contemporary capitalism, or as features inherent to its way of functioning. Albeit a certain awareness of its dysfunctionality consciously manifests "I know my existence would be much more serene and relaxed (being offline)", my student writes -, yet a sense of ineluctability appears to be connected to the hegemonic form of contemporary capitalist realism, i.e. communication.

Ten years after Fisher's gloomy reflections, the rise of social networking sites - and their hegemonic take over all aspects of digital communication - has made capitalist realism look even more inescapable. Paradoxically, it is in the communicative appropriation of the (once political) form of the "social" that this take over has been accomplished and made more pervasive. "What is the Social in Social Media?", Geert Lovink asks in his 2016 essay Social Media Abyss, mourning the loss of the primacy of politically engaged, class-related understandings of the social, in favour of mundane connotations rather evoking "interpersonal rubble [...], a loose collection of 'weak ties'" (Lovink 2016, 16).

Baudrillard (1983) located "the end of the social" as we know it in the combined action jointly performed by the masses and the media ${ }^{6}$. In Baudrillard's system of simulacra, the mass has turned into an abstraction, a sign that no longer has a material referent (the class, the proletariat, etc.) but only takes statistical existence in surveys and polls for measurability and predictability in the hands of "political demagogy" (Baudrillard 1983, 4). Meanwhile, media, the realm of the quintessentially spectacular, has abandoned the domain of meaning to embrace a mode of "constant emulsion" (Baudrillard 1983, 24), a non-stop dynamic of permanent transmission of messages

6 "The mass and the media are one single process. Mass(age) is the message" (Baudrillard 1983, 44). 
that, by virtue of this permanent circulation, are condemned to become mere contributions to the data stream". This phenomenon of "total dissemination, of a ventilation of individuals" generates a "space of connection" where "the rational sociality of the contract" (between the state and civil society, between the public and the private) abdicates in favour of the (spectacular, or post-spectacular) "sociality of the contact" (Baudrillard 1983, 83, my emphasis).

And yet it is only with Silicon Valley's techno-utopian dream of sharing at all costs, and with the participation by all means enabled by the so-called "social web" (O'Reilly 2005 ) that Baudrillard's prophetic idea of the sociality of the contact takes material shape becoming a set of productive relationships based on unpaid, underpaid, or volunteer labour developing free of charge and free of rights user-generated content to be circulated freely and gratis by virtue of crowdsourced tools such as ranking, hashtagging, liking, commenting. Here "sociality" is defined in terms of "making visible - and therefore commercially exploitable - the once hidden patterns of individual connections" (Della Ratta 2018, 184) that take the collective form of a network merely at a visual level. In reality, only a loose connection is established between the sociality of the contact and any sort of collective formation.

It is in Silicon Valley's utopian dream of techno-enabled sharing cultures, in its libertarian ideology of tech-powered free speech and democratic progress ${ }^{8}$ that the social hegemonic manifests - social is "the new black" of the digital - to be fully accomplished in what I call "the networked image" (Della Ratta 2018). The networked image is a visual (and political) formation defined by its sociality, that is its circulation, its exchange value, its capability of spreading itself throughout the social web, of establishing (social) relations with the latter's infrastructure, indifferently made by human or post-human subjectivities, algorithmic entities, databases, etc. Spreadability and visibility are the features defining the sociality of the networked image, together with the inner violence ingrained in the process of circulation?.

Violence is inherently connected to visibility, whether in the form of hypervisibility granted to widely circulated data - "poor images", as Hito Steyerl (2009) calls it -, or in the lack thereof, as content is redacted and forever extirpated from the online domain when non-complying to the platforms' terms-of-services and guidelines ${ }^{10}$. The uneven union between violence and visibility is no longer an exceptional situation peculiar to crisis zones. Syria is probably the most evident example where the hypervisibility of content circulation and the invisibility of content deletion are both present at the same time. Violence constitutes a feature of today's emerging visual political economy, characterised by a sociality that should be achieved at all costs and in spite of everything. It's the business and revenue model, the inner infrastructure of today's social platforms, in fact, that dictates the imperative of sharing, commodifying the latter in the exact moment in which the participation process happens.

Sharing economies are no longer what the founder of Creative Commons, Lawrence Lessig, so brilliantly conceptualised more than a decade ago, i.e. economies that are run alongside ideas of solidarity and non-monetary exchanges, and that could eventually coexist with commercial ventures forming an "hybrid economy" (Lessig

${ }^{7}$ Contribution is the word used by Dean (2010) to describe the process of voiding messages from meaning that takes place by virtue of non-stop circulation over the web 2.0.

${ }^{8}$ Barbrook and Cameron (1995) dubbed it "the Californian Ideology".

${ }^{9}$ I have extensively dealt with violence and visibility of the networked image in my analysis of the socially-mediated Syrian conflict in Della Ratta (2018.)

10 On the politics of commercial content moderation see Roberts (2019), Della Ratta (2020), and the documentary work "The Cleaners" (2018) by Hans Block and Moritz Riesewieck. 
2008). "Sharing is caring" 11 used to be Creative Commons' motto to encourage content exchange under a more flexible copyright regime. Paradoxically, today Creative Commons' licensed items have ended up being collected and used - lawfully - by commercially driven corporations to train facial recognition algorithms likely to be employed for military research projects and authoritarian repression ${ }^{12}$.

And yet what recently happened to Creative Commons databases is not an isolated episode or a flaw of the system, but rather a feature of the infrastructure of the sharing economy as it has been reconfigured by the private and commercially oriented platforms controlling the business of sharing. Today's sharing economy has managed to redefine the concept itself of sharing and inject the idea of monetary transactions and commodification within domains once exclusively devoted to solidarity and non-commercial exchanges ${ }^{13}$. This new hegemonic understanding of the sharing economy is private and commercially oriented by design.

Far away from the digital utopias that have characterized the first phase of the web 2.0 and its deep roots in the "Californian ideology" (Barbrook and Cameron 1995), today we witness the disruption of the digital commons. We mourn their disappearance within the domain of the sharing economy. We lament the loss of the social in the exact moment when the latter becomes the new triumphant, hegemonic media form.

\section{What is Digital Socialism?}

At the same time when the social becomes the "new black" of the digital, socialism is also subject to an operation of rebranding 2.0. Kevin Kelly, the founding executive director of Wired magazine and "a futurist adviser" 14 on Steven Spielberg's nightmare on surveillance cultures "Minority Report", marks the beginning of this process of upgrading the common sense with his seminal 2009 Wired piece "The New Socialism: Global Collectivist Society is Coming Online" (Kelly 2009).

In his semantic taking over of the concept and emptying it of all things political and class-related, Kelly argues that the emerging form of socialism is "uniquely tuned for a networked world" and far away from "your grandfather's socialism [...] It is not class warfare. It is not anti-American" (Kelly 2009). In Kelly's cyber-utopian rhetoric, digital social becomes in fact "the newest American innovation", a type of "socialism without the state", running over "a borderless Internet" and "designed to heighten individual autonomy and thwart centralization" (Kelly 2009). In his colourful techno-language, digital socialism replaces the tedious bureaucracy of the five-year plans with the "brilliant chaos of a free market", refashioning state factories into "desktop factories connected to virtual co-ops", and exchanging national production with peer production, "government rations and subsidies" with a "bounty of free goods" (Kelly 2009).

In his apology of digital socialism, Kelly feels to have to justify the choice of "such an inflammatory heading" and "redeem" it, as "technically it is the best word to indicate a range of technologies that rely for their power on social interactions" (Kelly 2009). In his over excitement for all things tech, when the masses "contribute labor without wages and enjoy the fruits free of charge" (Kelly 2009), that's socialism. As much as Amazon's Mechanical Turk is socialism, real-time Twitter and RSS feeds are socialism,

${ }^{11}$ One of the mottos of Creativecommons.org. I was Creative Commons' community manager for Arabic speaking countries from 2007 until 2013.

12 One of this (in)famous databases, MS Celeb, contained 10 million faces, and was used to train facial recognition systems for countries such as China (Murgia 2019).

${ }^{13}$ Take for example the commodification of the domain of hospitality by AirB\&B. See Morozov (2018).

14 That's the definition given by his Wikipedia page. 
unlimited free cloud computing and passionate opinions on the Huffington Post are socialism of the digital type that Kelly heralds as the new, perfect form of "cultural OS" elevating "both the individual and the group at once" (Kelly 2009).

One might excuse this over-enthusiastic apology by looking at the time in which it was authored, 2009, a year that was, for many, still full of digital promises and utopias. But Kelly believes so staunchly in digital socialism that he makes sure to declare his long-term view over the matter. Even if this phenomenon has not yet reached the mainstream at the time of his writing, "clearly the population that lives with socialized media is significant", Kelly emphasises. "The number of people who make things for free, share things for free, use things for free, belong to collective software farms, work on projects that require communal decisions, or experience the benefits of decentralized socialism has reached millions and counting" (Kelly 2009). And, he vigorously concludes, "revolutions have grown out of much smaller numbers" (Kelly 2009).

Ten years after this passionate attempt to redefine the meaning of socialism, the USA's enemy number one China seems to have learned the guru's lesson and embedded it into institutional forms, implementing an up-to-date version of state-led digital socialism. In 2020, the so-called "social credit system" will standardise the assessment of citizens' reputation producing a mechanism for ranking them according to their social and economic behaviours and sanctioning them if they fail to pay taxes on time, as much as if they do not show up after having booked a restaurant table or a hotel room. In this dystopian, Black-Mirror like ${ }^{15}$ framework, the Chinese government seems, in its turn, to have borrowed mechanisms of control and surveillance not from repressive institutions or authoritarian regimes, but precisely from the new digital social of social networking platforms. A way to visualise and quantify, therefore to evaluate, control, and sanction social relationships, that is possible to adopt at a state level and in such a pervasive, dystopian fashion only after the mechanism has become not just acceptable and familiar but, also, desirable for the global masses.

While this semantic redefinition is carried out, albeit in different ways, both by Silicon Valley's libertarian utopians and by China's new institutional form of authoritarianism concealed under the more attractive guise of the digital, the European Union responds to the hegemonic re-appropriation of the social by emphasising its citizens' rights to own their data and to protect their privacy. The General Data Protection Regulation (GDPR) ${ }^{16}$ is probably the most striking example of such a timid, apprehensive reaction to the takeover of the social, which reveals a lack of a proper understanding of this phenomenon happening at a global scale. GDPR attempts at building a defence against the aggressive pervasiveness of the digital social by giving individuals the (illusion of) control and ownership of their data, upon which they would enjoy the right to request a portable copy and also, under certain circumstances, the possibility to have them erased. However, this promise of opening "the algorithmic 'black box' to promote challenge, redress, and hopefully heightened accountability" (Edwards and Veale 2017, 18) might just result into yet another "transparency fallacy" (Edwards and Veale $2017,43)$, as there are complicated legal and infrastructure-related issues that might prevent the granted rights to be properly exercised by their holders.

And yet even these legal or infrastructural impediments are not what is really at stake with the GDPR and similar policies. Its underlying problem is rather, in my view,

${ }^{15}$ See the series episode 'Nosedive' from season 4.

16 See the official document http://data.consilium.europa.eu/doc/document/ST-9565-2015INIT/en/pdf 
an approach responding to the pervasive appropriation of the digital domain that renders all things digital "social" by simply reaffirming values such as ownership and property. The stark contradiction between data that have constantly to move and circulate - that have to be "spreadable" (Jenkins, Ford and Green 2013) - as per the business model of all things social, and the right to own and control such fluctuating, pervasive, and ever-multiplying immaterial goods, becomes apparent here. It's the overall acceptance of a giant money machine and revenue-making system in the hope of regaining control of it by tweaking some small details. It's a David and Goliath situation, where the actual little stone being thrown at the latter's forehead does not affect the whole gigantic immaterial apparatus firmly in place.

The contradiction inherent in a GDPR-like approach is that while we struggle to regain little bits of ownership and control over our data, the "feedback infrastructure" (Morozov 2019) stays firmly in the hands of platform capitalism. This rights-based attitude and the values themselves that it claims to defend and protect - property, ownership and privacy - are the core of the problem, not its antidote. Claiming back ownership and privacy does not challenge the system, instead it seeks to mitigate the worst effects of communicative capitalism, protecting small territories of individual freedoms against a market that stays as greedy as ever (if not more), appealing to individual personal rights and responsibilities rather than addressing a political collective.

How is it possible to redefine socialism if we are still acting within the domain of individual rights rather than collective solidarity? How can we be pleased and satisfied with such small, insignificant forms of counterbalancing the over power of the social hegemonic, if these very forms still pertain to the domain of communicative capitalism and its values? How can we rework socialism into a brand-new digital arrangement if we are entrapped within capitalist realism, so enmeshed in its perverse and pervasive mechanism that we are unable to unleash our imaginative power?

\section{What Digital Socialism is Not: Beyond the Knowledge Economy}

In the imaginative effort we should undertake to imagine a form of digital socialism that goes beyond Silicon Valley's techno-utopianism à la Kelly or China's dystopian ranking system, the starting point is to take a distance from the knowledge economy ${ }^{17}$. We do not know what digital socialism is or could be, yet surely it has nothing to do with knowledge production. If the latter, in fact, lies at the very core of communicative capitalism functioning as its nurturing engine, then how can it be at the same time constitutive of digital socialism? Is a different form of knowledge, just because of it being supposedly built around a collaborative and peer-produced process, the right antidote to communicative capitalism? Are Wikipedia, and the over celebrated collaborative aspect behind its "wikinomics" 18 , the only possible shape that a "socialist" digital environment could eventually embrace, the face of the upcoming digital socialism?

I want to shift the perspective of the conversation and look for something else than an allegedly more "socialist" form of immaterial knowledge production to imagine the foundations of digital socialism. I would like to engage in an exercise of creative imagination to go beyond the constraints of capitalist realism and, instead of locating an alternative way, a more collectively oriented mode of knowledge production, just take a detour and think outside the box of this very knowledge production. In my view, the

${ }^{17}$ For a critical discussion of the knowledge economy see Peters $(2019,2001)$.

18 This "wikinomics", an economy based on networking, collaboration and peer production, is heavily criticized by Fuchs (2008) not only for supporting a regime of accumulation that brings about precarious labour, but also because of its ideological aspects. 
problem lies precisely within the so-called knowledge economy, a fundamental trait of contemporary capitalism condemning labour to produce and distribute "information, communication, social relationships, affects" (Fuchs 2010, 142).

In the early days of web $2.0^{19}$, a literature enthusiastically supportive of a networked, cooperative, peer-based production had imposed itself 20 , putting forward an idea of value rooted in social relations and pushing the belief that "new forms of technologicalenabled openness, especially emergent social media that utilizes social networking, blogs, wikis and user-created content and media" (Peters 2019, 3) would provide the ground for a radically new conception of knowledge based on the "sharing and caring" for the commons. However, not only has Silicon Valley's platform capitalism dramatically changed the overall meaning of the sharing economy and transformed the once happily collaborative crowd of volunteering "peers" into an army of frustrated unpaid or underpaid labour that has now to deal with the unintended, disastrous consequences of finding the commons commodified and exploited. Furthermore, the fact of understanding the commons merely in terms of juridical zones regulated by a less rigid intellectual property and by a more relaxed attitude toward ownership, does not take distance from a rights-based approach, therefore stays relegated within the domain of capitalist realism.

The problem of "equalising access to communication services" focuses on just one aspect of the question, without eliminating or even weakening "other types of inequality" (Morozov 2015). Quite the opposite, in fact: by helping the socialisation of knowledge, open access, together with the participation, collaboration, and peer production that it enables, and combined with a more flexible approach to intellectual property, this model ends up strengthening the sharing paradigm upon which communicative capitalism thrives. Therefore, the web-powered socialisation of knowledge and "knowledge socialism" (Peters 2019) do not equal socialism. Rather, these developments push forward the apparently innocent face of a "don't be evil" ${ }^{21}$ capitalism, hiding its stellar profits under the banner of the Californian ideology's freedom of speech and participation dreams. Open access to knowledge and the wikinomics is definitively not what will lead us toward digital socialism. We have to look elsewhere.

In a recent piece in which he attempts to locate digital socialism in the computational age, Morozov criticizes the "new deal on data" (a GDPR-like approach) as something aiming at introducing a "modicum of fairness" in the far west of the digital economy, and selling the fantasy of "imagining users as anything other than passive consumers" (Morozov 2019, 33-34). Such initiatives, Morozov maintains, are "important to guarantee the future of digitalized capitalism" (Morozov 2019, 34) by tweaking it without undermining its very structure, as they frame the main problem of the latter's inequalities always in terms of ownership and individual property rights, which are in fact the pillars of the liberal personhood. While these initiatives focus on regaining (some) control over these rights, they fail to consider the fact that "the ownership and operation of the means of producing 'feedback data' are at least as important as the question of who owns the data itself" (Morozov 2019, 52). Ultimately, they ignore the feedback infrastructure and the firm hands of the very few tech giants controlling it.

Rightly emphasising the fact that no radical transformation is ever going to take place if the feedback infrastructure remains under the current Silicon Valley privateownership model, Morozov's piece engages in sketching out a plan for the progressive

19 The definition 'web 2.0' comes from a blog post authored by O'Reilly (2005).

20 See for example Benkler (2006) or Lessig (2006, 2008).

${ }^{21}$ Google's former motto, once at the top of the company's code of conduct. In 2015, after the restructuring into Alphabet Inc., the motto was changed into "Do the right thing" (Barr 2015). 
left to find ways "to deploy 'feedback infrastructure' for new, non-market forms of social coordination" (Morozov 2019, 54), and to discover "other social arrangements, apart from competition" (Morozov, 55). He suggests three possibilities to do so: firstly, using "solidarity as a discovery procedure" as to "detect new needs and ways to satisfy them through non-market mechanisms" (Morozov 2019, 54). Hackathons, a sort of tech marathons based on the idea that a certain issue identified by some actors (e.g. NGOs) will find a solution if socialised with a group that has a specific knowledge, is the example brought up by Morozov to suggest that solidarity could lead the process of problem solving through altruism rather than through competition. Secondly, "designing non-markets" (Morozov 2019, 57) to coordinate matters of social interest going beyond the price mechanism, which Morozov illustrates by pointing out Alvin Roth's work on matching organ donors with potential recipients. And thirdly, focusing on coordination in the economic sphere by putting into place what he calls "automated planning" (Morozov 2019,55$)$.

This is, perhaps, the essay's most visionary section where Morozov builds on American radical economist Daniel Saros' work, which he calls "'guild socialism' in the era of Big Data" (Morozov 2019, 63). Saros' path toward a socialist economy for the digital age is kind of tortuous, involving the building of a "'General Catalogue', something in between Amazon and Google, where producers, who are organized in guildlike 'worker councils' -worker-run startups if you will - list their products and services in a way that would be familiar to users of Apple's App Store or Google's Play Store" (Morozov 2019, 64). Without going too much into the details of a complex system where users have to register their needs during a specific production period and then try to stick to those envisaged needs in order to get some bonuses (which are given also to those who consume less than average or to those who stay in the same job for a long time), the issue with Saros' model is not just, as Morozov underlines while still praising the economist's work, that it offends "the eco-socialist creed" by emphasising consumption, or that it involves the "much-maligned quantification" as it heavily depends on feedback mechanisms and ratings (Morozov 2019, 64-65).

Actually, a much bigger issue lies with the formulation of Morozov's argument itself. His language and theoretical apparatus are entirely (and, probably, unconsciously) borrowed from communicative capitalism, even when they attempt at defining how socialism would look like. Expressions such as feedback mechanisms, ranking system, matching, or worker-run start-ups are the offspring of the colonisation of the imagination (and of language) pushed forward by the hegemonic social and the values of the contemporary sharing economy. The continuous references to an Amazon-like planning system or to services designed alongside the model of the Apple or Google's app stores reveal the challenge of imagining anything beyond capitalist realism, even in the context of a sophisticated essay of critical theory aimed at defining digital socialism.

In a recent workshop carried out in the Roman neighbourhood of Torpignattara by the collective Human Ecosystems Relazioni (H.E.R.) ${ }^{22}$, co-founders Salvatore laconesi and Oriana Persico have underlined the troubles encountered in attempting to collectively design an A.I. functioning with relational, non-extractivist data. "When we ask people to brainstorm about how they would like their neighbourhood A.I. to be and to do, they cannot but imagine something service-oriented. Thinking about data as resources that are extracted from us in exchange of free services is so deeply rooted in us that it's extremely challenging even to just imagine how relational-data would look

${ }^{22}$ See their website https://www.he-r.it 
like"23. "It is easier to imagine the end of the world than the end of capitalism", Jameson bitterly noticed $(2005,199)$.

Morozov's piece, although trying to locate possible paths toward re-appropriating the feedback infrastructure in the direction of non-market non-competitive exchanges, remains entrapped within the language, metaphors and imaginative power of communicative capitalism. Furthermore, all the examples given to illustrate those possible paths operate within and not outside the latter, within the boundaries of knowledge production and not beyond. They are deeply rooted in computation and quantification centred beliefs, and hint at a cybernetic model of society.

I agree with the end goal of Morozov's essay and therefore I wonder: why should we take inspiration of a planning system from Amazon? Why should we borrow the language through which we describe our desires and wishes for a non-market centred society from capitalism itself? Is it possible to envisage and advocate for a capitalismfree way of rethinking digital socialism?

The biggest problem with Morozov's formulation of the latter is his emphasis on knowledge production, albeit of a different nature. The biggest problem with knowledge production is that it overemphasises the symbolic aspects and the immateriality of the commodity, shaping an ideology of the digital being "non-rivalrous, infinitely expansive, discrete, aspatial, and recombinant" (Quah, in Peters 2019, 2). Thinking about digital socialism requires, instead, to get beyond immateriality and abstraction - therefore, beyond knowledge production - and rather focus on the material production of subjectivities and their ways of being in the world.

Queer philosopher Paul B. Preciado identifies a shift in contemporary capitalism from knowledge production toward what he calls "the pharmapornographic control of subjectivity" (Preciado 2013, 39) and its making, implemented through a set of technologies of the body (from endocrinology to genetic engineering) that are "microprosthetic" and "incorporated" (Preciado 2013, 77-78) . They can be "inhaled" and "injected" (Preciado 2013, 77), they penetrate and infiltrate our body taking control until it "no longer inhabits disciplinary spaces but is inhabited by them" (Preciado 2013, 79). For Preciado, it is precisely when technology is no longer an extension of man but rather the other way around, and when the organic needs technology in order to be (re)produced as organic, that the body's political potential can finally unfold. His mutant body is a living testimony of the latter, as in the very moment in which it needs the pharmapornographic regime to become a subject and be recognised as subjectivity, it revolts against it by hacking its system of binaries and embracing multiplicity and queerness.

The body and the production of subjects and subjectivities are today's battlefield. Taking a distance from the knowledge economy and its emphasis on immateriality and abstraction, I want to follow the path explored by queer and feminist theories to engage with the materiality of contemporary capitalism in order to locate spaces that contemporary socialism could possibly inhabit. Reinventing the social and rethinking socialism should have less to do with tweaking the process of knowledge production and regaining control over the ownership of its end product (data). Instead, it should be more focused on the production of the body, subjectivities, and the ways in which they materially exist in the world.

${ }^{23}$ Personal interview, January 2019, Rome. 


\section{What Digital Socialism Could be About: Ethics of Care}

Queer and feminist scholarship and analyses might prove useful antidotes to the violence of abstraction that is inherent in the data-driven knowledge-economy. They can provide ways to look at contrasting communicative capitalism not from the perspective of individually-centred property-based rights, but from collective and relational modes of being in the world. They can help us to locate digital socialism in spaces other than the production of the immaterial.

A concept that I would like to borrow from feminist scholarship engaged in rejecting "traditional male reasoning" (Koehn 1998, 4) and underlying the latter's embeddedness in norms and stereotypes of patriarchal societies, is that of care. As "care is both value and practice" (Held 2006, 9), care and the work of care cannot be separated: they are deeply connected and interdependent. The work of care has traditionally occupied disadvantaged workers - women, migrants, people of colour - in activities related to social reproduction and reproductive labour, i.e. "the set of tasks that together maintain and reproduce life, both daily and generationally" (Hester 2018, 345), spanning from the care for others (childcare, elder care, etc.) to the maintenance of the infrastructure necessary to support life and work life (cleaning, etc.) to species reproduction (bearing children).

Whether being carried out in private spaces such as the household by unpaid workers, or in public places such as hospitals and remunerated, reproductive labour cannot be separated from the idea of an ethics of care. This has been made the object of several theoretical reflections in feminist studies ${ }^{24}$, many of which emphasise them being "a serious and important alternative to dominant Kantian and rights-based ethics" (Robinson 2011, 21) and, in general, a powerful antidote against the "quasi-mathematical form of ethical reasoning" (Koehn 1998, 2) imposed by male philosophers. Ethics of care are characterised by an understanding of the self that is relational rather than individualistic, placing human and intimate relations at the centre of life, in stark opposition to "legalistic contractual thinking, so favored in traditional analyses" which might in fact "alienate persons, rather than draw them together" (Koehn 1998, 6).

This emphasis on relations rather than rights, on sociality rather than individuality, on interdependence rather than independence, on particularity, connection, and context rather than the universality and abstraction of legalistic contractual thinking, is what I would like to offer to the reflection on digital socialism. Ethics of care present a radical critique of liberal individualism and its values ${ }^{25}$. The work of care in itself - through which work at large is made possible, through which all of us are made possible as workers and humans - is a reminder that the independent, autonomous, rational individual is a fantasy deeply imbued with patriarchal ideologies. Care work is, in fact, "dependency work" (Held 2006,14), as it puts into bold relief how we all depend one on another, how we are all connected, related and interdependent. It makes a powerful detour from the rights-based approach, from the abstraction and immateriality of the knowledge economy. It restores materiality and relationality as central elements to the discussion on how digital socialism could be looked at, instead of just being imagined as a timid reformist attitude within the domain of communicative capitalism's knowledge economy.

Apart from it shaping an ethics that is not abstract and universal but contextual and intimately connected to labour - care and the work of care, care is the work of care there is an aspect of contemporary care that offers another interesting angle to the

${ }^{24}$ A good overview can be found in Koehn (1998) and Held (2006).

25 See for example Held $(2006,13-15)$. 
debate on digital socialism. Reproductive labour, which has been traditionally understood as women's work, and which is increasingly occupying a crucial sector in contemporary market economies to the extent that we can speak of a "care economy" (Hester 2018, 346-347), is threatened by the growing automation that is causing an impending "crisis of work" (Hester 2018, 344). This dramatic technological change in the job market is investing not just high-income economies, but also developing countries, further strengthening power inequalities that are already in place.

The domain of the care economy, which once seemed the exclusive territory of feminised (paid, underpaid, or unpaid) work, is now at risk of being colonised in its turn by the abstraction and immateriality of automation. The New York Times refers to a recent experiment in France where Zora, a robot caregiver, has replaced humans in assisting elderly people (Satariano, Peltier, and Kostyukov, 2018). Care.Coach, a "game-changing innovation for aging and geriatric care that leverages the best of both human and technological capabilities" 26 , is successfully providing patients with pet avatars that assist with psychosocial support $24 / 7$ and from a distance, while "conversations of a clinical nature are automated through software algorithms that implement clinical best practices"27.

"The care.coach approach is a thoughtful combination of digital technology and genuine human connection... a creative solution to the shortage of qualified caregivers in the US" ${ }^{28}$, says Tom Grape, chairman and CEO of the Benckmark Senior Living company. Actually, rather than due to a shortage of qualified caregivers, the business of automated care is on the rise because of its cost-effectiveness in a healthcare market, like the US, which is highly commodified and competitive. "Human contact is now a luxury good" (Bowles 2019), the New York Times has titled, hinting at the increasing phenomenon of automation and screen-mediation taking over all domains of human life for the working class. In stark contrast, elites enjoy the privilege of disconnecting when they wish to take a distance from technology, still being able to purchase nonautomated, more costly human labour.

Automation's takeover of all aspects of human life, including that of care which once was the domain of women's labour and of relational, interdependent, sociality-centred ethics, certainly rings an alarm bell. However, considering the matter more closely, a striking similarity emerges between the expanding market of automation and the contemporary care economy. Often times, in fact, tech-powered automation requires some sort of human labour to function properly. Care.coach's virtual pets, for example, are voiced by staff working in the Philippines (Mannion 2017), a country increasingly becoming, as Sara T. Roberts' (2019) brilliant work highlights, a world hub for operations related to commercial content moderation, from "cleaning" 29 the web from pornography, violence and hate speech, to contributing to tasks of low-level automation, such as the ones required by automated healthcare.

In both cases, such duties are performed by underpaid labour, migrants and women, or people located in developing nations - the case of the Philippines is exemplary of a country in which an entire sector of the population significantly works according to the time zone and the cultural values of another country, the US (Roberts 2019). Often times, this exploited, cheap labour is subject to psychological repercussions for the kind of sensitive work they have to perform on a daily basis, whether cleaning the

\footnotetext{
${ }^{26}$ See the website https://www.care.coach/about.html

$27 \mathrm{https}: / /$ www.care.coach

28 https://www.care.coach

${ }^{29}$ As the title of a recent documentary on this topic, "The Cleaners" (2018) by Hans Block and Moritz Riesewieck.
} 
web from child pornography and terrorism-related content, or assisting elderly people with depression and all sorts of syndromes. Almost always, this workforce is invisible. Not only because it disappears in the eyes of the end user by virtue of the automation process, but also as the workers are obliged to sign non-disclosure agreements with the company who hires them and who does not wish them to address these practices in public ${ }^{30}$.

It is precisely in this invisibility that we should be able to find a connection, following Anne Boyer's insight: "the work of care and the work of data are quiet, daily, persistent, and never done" (Boyer 2015). We do not get to see the women, the migrant, the unprivileged who perform the care work in the form of unpaid or underpaid labour, often in private spaces, far away from public eyes. These figures are erased by the ideological glossiness of the knowledge economy presupposing and assuming the existence of independent, completely autonomous individuals - a fiction embedded in contemporary neoliberal capitalism. As much as we do not get to see the exploited workers from the Global South or from unprivileged and poor areas of the Global North, who are constantly monitoring and cleaning our social media posts, which we understand as textual manifestations of our rights to freedom of expression; or those who assist our elderly remotely at any time of the day, disguised as coloured tech avatars as if they were lacking material existence, empty stomachs to fill, families to feed, bills to pay. The work of care and the work of data go unnoticed until they are missing. "A dirty house attracts more attention than a clean one" (Boyer 2015), and the work of "cleaning" the web from the obscenities of free speech should never be paused, as otherwise the toxic waste of our alleged freedom of expression would immediately emerge to the surface.

In automation, in the quantification process, these postcolonial bodies are erased and condemned to disappear, subject to the violence of abstraction that is inherent in data and knowledge production. Where does the non-quantifiable go? How does the non-quantifiable inhabit the domain of the digital? How do we restore the materiality of these bodies, how do we rehabilitate personhood in the digital, through the digital?

Capital is trying to colonise our bodies and render them into data and abstraction, into invisible yet functioning units. It is at the intersection between the work of care and the work of data that we should initiate a reflection on digital socialism, in this very material overlap of flesh and bones, bits and pixels, melted together into a concrete political formation that we have not fully explored yet.

\section{References}

Barbrook, Richard and Andy Cameron. 1995. The Californian Ideology. Mute 1 (3). Accessed 29 November, 2019. https://www.metamute.org/editorial/articles/californian-ideology

Barr, Alistair. 2015. Google's “Don't Be Evil” Becomes Alphabet's "Do the Right Thing”. The Wall Street Journal, 2 October. Accessed November 29, 2019. http://blogs.wsj.com/digits/2015/10/02/as-google-becomes-alphabet-dont-be-evil-vanishes/

Baudrillard, Jean. 1983. In the Shadow of the Silent Majorities ... or The End of the Social and Other Essays. New York: Semiotext(e).

Benkler, Yochai. 2006. The Wealth of Networks: How Social Production Transforms Markets and Freedom. New Haven, CT: Yale University Press.

Bowles, Nellie. 2019. Human Contact Is Now a Luxury Good. The New York Times, 23 March. Accessed 29 November 2019. https://www.nytimes.com/2019/03/23/sunday-review/human-contact-luxury-screens.html

${ }^{30}$ Which makes this subject extremely difficult to study (see Roberts 2019). 
Boyer, Anne. 2015. Data's Work is Never Done. Guernica, 13 March. Accessed 29 November, 2019. https://www.guernicamag.com/anne-boyer-datas-work-is-never-done/

Briziarelli, Marco and Emiliana Armano, eds. 2017. The Spectacle 2.0: Reading Debord in the Context of Digital Capitalism. London: University of Westminster Press.

Dean, Jodi. 2010. Blog Theory: Feedback and Capture in the Circuits of Drive. Cambridge: Polity Press.

Dean, Jodi. 2005. Communicative Capitalism: Circulation and the Foreclosure of Politics. Cultural Politics 1 (1): 51-74. Accessed 29 November, 2019. https://commonconf.files.wordpress.com/2010/09/proofs-of-tech-fetish.pdf

Debord, Guy. 1994. The Society of the Spectacle, 3rd edition. New York: Zone Books.

Della Ratta, Donatella. Forthcoming. Through the Looking-Glass. Researching the Online Self, from Autoethnography to Empathic Criticism.

Della Ratta, Donatella. 2020. Why the Syrian Archive is No Longer (Only) About Syria. In The Arab Archive: Mediated Memories and Digital Flows, edited by Donatella Della Ratta, Kay Dickinson and Sune Haugbolle. Amsterdam: Institute of Network Cultures (epub).

Della Ratta, Donatella. 2018. Shooting a Revolution: Visual Media and Warfare in Syria. London: Pluto Press.

Edwards, Lilian and Michael Veale. 2017. Slave to the Algorithm? Why a "Right to an Explanation" Is Probably Not the Remedy You Are Looking For. Duke Law \& Technology Review 18. http://dx.doi.org/10.2139/ssrn.2972855

Fisher, Mark. 2009. Capitalist Realism: Is There No Alternative? Winchester: Zero Books.

Fuchs, Christian. 2010. Class, Knowledge and New Media. Media, Culture \& Society 32 (1): 141-150. doi:10.1177/0163443709350375.

Fuchs, Christian. 2008. Book Review of "Wikinomics: How mass collaboration changes everything" by Don Tapscott and Anthony D. Williams. International Journal of Communication, $2,1-11$.

Han, Byung-Chul. 2015. The Burnout Society. Stanford, CA: Stanford University Press.

Held, Virginia. 2006. The Ethics of Care: Personal, Political and Global. Oxford: Oxford University Press

Hester, Helen. 2018. Care Under Capitalism: The Crisis of "Women's Work". IPPR Progressive Review 24 (4), https://doi.org/10.1111/newe.12074

Jameson, Fredric. 2005. Archaeologies of the Future: The Desire Called Utopia and Other Science Fictions. London and New York: Verso.

Jenkins, Henry, Sam Ford, and Joshua Green. 2013. Spreadable Media: Creating Value and Meaning in a Networked Culture. New York: NYU Press.

Kelly, Kevin. 2009. The New Socialism: Global Collectivist Society is Coming Online. Wired, 22 May. https://www.wired.com/2009/05/nep-newsocialism/

Koehn, Daryl. 1998. Rethinking Feminist Ethics: Care, Trust and Empathy. London: Routledge.

Lessig, Lawrence. 2008. Remix: Making Art and Commerce Thrive in the Hybrid Economy. London and New York: Bloomsbury.

Lessig, Lawrence. 2006. Code and Other Laws of Cyberspace, Version 2.0. New York: Basic Books.

Lovink, Geert. 2016. Social Media Abyss: Critical Internet Cultures and the Force of Negation. Cambridge: Polity Press.

Mannion, Lee. 2017. Meet Bella, a Digital Pet Caring for the Elderly With Purrs and Companionship. Reuters, 23 October. Accessed 29 November, 2019. https://www.reuters.com/article/us-usa-tech-social-care/meet-bella-a-digital-pet-caring-for-the-elderly-with-purrs-andcompanionship-idUSKBN1CS1FZ

Mayer-Schönberger, Viktor and Thomas Ramge. 2018. Reinventing Capitalism in the Age of Big Data. New York: Basic Books.

Morozov, Evgeny. 2019. Digital Socialism? The Calculation Debate in the Age of Big Data. New Left Review 116 (March-June), https://newleftreview.org/issues/ll116/articles/evgenymorozov-digital-socialism 
Morozov, Evgeny. 2018. From Airbnb to City Bikes, the "Sharing Economy" Has Been Seized by Big Money. The Guardian, 27 November. https://www.theguardian.com/commentisfree/2018/nov/27/airbnb-city-bikes-sharing-economy-big-money

Morozov, Evgeny. 2015. Silicon Valley Likes to Promise "DigitalSsocialism" - But It Is Selling a Fairytale. The Guardian, 1 March. https://www.theguardian.com/commentisfree/2015/mar/01/silicon-valley-promises-digitalsocialism-but-is-selling-a-fairy-tale

Murgia, Madhumita. 2019. Microsoft Quietly Deletes Largest Public Face Recognition Data Set. Financial Times, 6 June. Accessed 29 November 2019. https://www.ft.com/content/7d3e0d6a-87a0-11e9-a028-86cea8523dc2

Murphy, Samantha. 2013. Report: $56 \%$ of Social Media Users Suffer from FOMO. Mashable, 9 July. Accessed 29 November, 2019. https://mashable.com/2013/07/09/fear-of-missingout/?europe=true

O'Reilly, Tim. 2005. What is Web 2.0: Design Patterns and Business Models for the Next Generation of Software. O'Reilly Media, www.oreilly.com/pub/a/web2/archive/what-isweb-20.html.

Peters, Michael A. 2019. Digital Socialism or Knowledge Capitalism? Educational Philosophy and Theory 52 (1), https://doi.org/10.1080/00131857.2019.1593033

Peters, Michael A. 2001. National Education Policy Constructions of the "Knowledge Economy": Towards a Critique. Journal of Educational Enquiry 2 (1), 1-22. https://pdfs.semanticscholar.org/4c0e/6e322604088287ced23e42945fe5fe014d71.pdf

Preciado, Paul B. 2013. Testo Junkie: Sex, Drugs and Biopolitics in the Pharmacopornographic Era. New York: The Feminist Press.

Roberts, Sarah T. 2019. Behind the Screen: Content Moderation in the Shadows of Social Media. Yale: Yale University Press.

Robinson, Fiona. 2011. The Ethics of Care: A Feminist Approach to Human Security. Philadelphia: Temple University Press.

Satariano, Adam, Elian Peltier and Dmitry Kostyukov. 2018. Meet Zora, the Robot Caregiver. The New York Times, 23 November. Accessed 29 November, 2019. https://www.nytimes.com/interactive/2018/11/23/technology/robot-nurse-zora.html

Srnicek, Nick. 2016. Platform Capitalism. Cambridge and Malden: Polity Press.

Steyerl, Hito. 2009. In Defense of the Poor Image. E-flux Journal, 10. Accessed 29 November, 2019. www.e-flux.com/journal/10/61362/in-defense-of-the-poor-image.

Wark, McKenzie. 2013. The Spectacle of Disintegration: Situationist Passages Out of the Twentieth Century. London and New York: Verso.

Zuboff, Shoshana. 2019. The Age of Surveillance Capitalism: The Fight for a Human Future at the New Frontier of Power. New York: Public Affairs-Hachette Book Group.

\section{About the Author}

Donatella Della Ratta

Donatella Della Ratta is a scholar, writer, performer, and curator specializing in digital media and networked technologies, with a focus on the Arab world. She holds a PhD from the University of Copenhagen and a postdoc from The Annenberg School for Communication, University of Pennsylvania. She has managed the Arabic speaking community for the international organization Creative Commons from 2007 until 2013, and is a former Affiliate of the Berkman Klein Center for Internet and Society at Harvard University. She is co-founder and board member of SyriaUntold.com, recipient of the Digital Communities award at Ars Electronica 2014. Shooting a Revolution: Visual Media and Warfare in Syria (Pluto Press, 2018) is her latest essay. 